\title{
A Study on Innovative Design of Dancesport Choreography
}

\author{
Tangjuan \\ The Art Institute of Xichang College Xichang City, Sichuan Province, China \\ Ningyuan Bridge Education College, Sichuan Province, China \\ tangjuanxcc@163.com
}

\begin{abstract}
With the growing development of dancesport, people have gradually had more knowledge about dancesport choreography. Dance choreography refers to sequences of movements and steps that are created by choreographers and performed by dancers usually to musical accompaniment in line with the rules of contests and based on dancers' athletic capability, which are rationally conceived, designed and processed with music as per the required time, fields, extents, routes and directions; it is an innovative activity combining together with visual thought. In this paper, the author specifically explores the elements and structures of an entire set of choreography and its innovation, which plays an active role in upgrading the theory and practice of dancesport in education trainning.
\end{abstract}

Index Terms - dancesport; choreography, innovative design, education trainning

\section{Characteristics and Principles of Dancesport Choreography}

Choreography denotes arrangements in a certain order. Dancesport choreography organizes single movements or routines into a complete set of movements and steps rationally and coherently in certain period of time, field, extent, route and direction. The choreographer shall conceive, extract, integrate and improve the dance routines within a certain space and period of time based on the capability of dancers, which is an interesting and innovative activity. As an integration of PE, dancing and art, dancesport combines the features of PE and artistic rules.

\section{A. Characteristics of Dancesport Choreography \\ 1) Competitiveness}

In terms of its category, dancesport falls into skill oriented events with difficulty and beauty, full of typical characteristics. Dancesport, as it is, has the competitiveness of victory or defeat and performance, requiring both normative steps and contents beyond the skills. The competition focuses on how to perform more beautiful and better, and its movements shall be skillful, beautiful, stable and innovative, with the requirements similar to gymnastics, diving, gymnastics rhythmic and figure skating. Dance routines and combination show more versatile, requiring not only the right direction in going up and down, swinging, body-center move, but also the balance control to show the body, as well as how to successfully present each light and stretched movement that feast the audience's eyes through the dance with bones, joints and muscles[1].

2) Artistic Appreciation Value

Dancesport is an integration of both sport and dance, which makes it full with appreciation value in addition to athletics. Enjoyment of beauty is the direct feeling when audiences are watching the dance, which is also one judgment standard and a fundamental element of a successful dancesport. In the competition, for dancers with comparable level, the one who bring the audience stronger sense of beauty may finally achieve victory. In significant international sport games, the top two winners may only differ in performance of different dance styles and artistic attraction.

\section{B. Principles of Dancesport Choreography \\ 1) Harmony of Movements}

Under the guide of contest rules, arrangement of complete dance routines shall be consistent with the music accompanied and dance style. Different dances require different music and rhythms. The must tempos, intensity and melody shall all be taken into full consideration, and choreographer shall well manage the pace, intensity of movements and consider whether the movements correspond to the required emotion performance[2].Cooperation methods are attached much importance in both standard Dancesport and Latin dance. Considering the entire set of movements, good dancers must be skilled, typically harmonious in characteristics. They should not only present the features of individuals but also coordination with their partners, which determines the overall level of a dancing team.

\section{2) Personalization}

Dancers participating in choreography are selective. Personalities of dancers differ vastly, unique in terms of artistry. Only when a dancer builds his or her own unique movements and expressive force will he or she possess a stronger sense of artistic attraction. On the premise of meeting basic requirements of different dancesport types, dancers keep pursuing and expressing advantages and characteristics of his or her own, hence choreography based on these merits will be distinctive and deeply impress the audience.

\section{Process of Dancesport Choreography}

\section{A. Conceiving Stage}

After receiving a choreography task, it is the first thing to get much basic information of the player, such as skill level, personality and competition class to form a generally idea about the entire movements. For movements of individuals, some factors should be taken into consideration, for instance, music, overall styles of routines, movement patterns, difficulty degrees, movement quantity and the change of dancing rhythms; for formation dancing, the formation patterns and change should 
also be taken into consideration. With a general scheme, choreography goes to next stage, namely, selection and creation of movements.

\section{B. Movement Selection and Creation}

Dancesport mainly consists of general movements (required by copper and silver level), highly skilled movements (gold level), self-created movements (turning around forcefully, splitting, back bending etc). When creating a set of movements, a choreographer should first decide the overall difficulty degree and select required movements carefully; then he shall determine the quantity and types of rest movements, such as connecting movements, combining movements and performing movements etc. In a word, movements should be selected based on relevant needs and capability of the dancers.

\section{Dance Routines Design and Innovation}

The first step in this stage is to select music materials, determining time span and music style. Modern Dance consists of route A (long route) and route B (short route), and suitable movements should be selected in accordance with lengths of the two routes, for example, dancers could do some progressive walks on route A but some dressage or still steps on route B or at the four corners. Having completed small-group movements, we could connect several small step groups together and transform them into a large content of combination consisting route $\mathrm{A}$ and route $\mathrm{B}$, finally organize a distinctive overall routine. We should make full use of the dancing field and connect either steps or routines in a rational and smooth way. [3]Similarly, in formation dancing, we should also connect single steps into small routines, forming into small units with different formation which is later created into different figures that are generally used in formation dancing, such as straight line, parallel line, triangle, circle, spoon, rhombus, V-shape and arrow. Then for the transforming and moving methods, it generally consists of moving in one direction, negative direction, cross direction, clockwise direction and anticlockwise direction etc. In a word, the overall formation should transform naturally and reasonably. Additionally, Modern Dance and Latin Dance should be respectively considered[4].

\section{Components of Innovative Dancesport Choreography}

\section{A. Innovative Design of Music Elements}

Dancesport integrated into music are present in tempos and beats. Tempos also have expression elements, such as strong and weak, heavy and light. Choreographers try to make music visual and movements expressive. However, movements cannot be simply adhered to the music during a period of time. Instead, they should be in harmonious integration[6].

The selection and composition of music shall depend on players' skills and characteristics, and choreographer shall reasonably arrange the time duration and alternate times of each dance type. It is recommended to select dance music that sound elegant, beautiful and grant, with clear beats. A powerful artistic effect relies on a reasonable composition of pace, intensity, peace or orgasm of music choreographers choose. To make sure the dance music is innovative, professional composers or bands are always in need to play the music. The coherence between two pieces of music must be clear and natural so that they sound as a whole piece, which lays a solid foundation for performance of the complete movements arranged.

\section{B. Innovative Design for Aesthetic Constituents \\ 1) Coordination and Formation}

Coordination and formation between dancing partners are always designed on the basis of aesthetic compositions, hence the each pause could be a fine piece of photograph, for every movement is arranged elaborately by the choreographer. From the video records of 2012 British Blackpoll Dance Festival, the author found that cooperation and formations tend to be much more ingenious, distinctive and innovative, comparing with common ones.

\section{2) Formation and Transformation}

Formations of movements in dancesport are always versatile in terms of moving route, separating or uniting every now and then. Transformation in group dancing shows the characteristics of aesthetic composition, which reflects a grant momentum and powerful feeling as dancers change their steps and positions timely. There exist different kinds of geometric formations in formation dancing, circle, straight line, oblique line, rhombus, broken line and double lines, which transform by time.

\section{3) Costumes}

Costumes for Dancesport should be bright in color and fashionable in style, to show the graceful figure of the performers; a good match of costumes for dancers in different genders will be vastly appreciated by the audience. Costumes for males can be colorful, even their trousers has gotten rid of the monotonous color of black or deep blue, but whatever they are dressed in should always match their female partners' costumes. Choreographers should pay more attention to composition of colors in costumes dancers dress. They shall consider the characteristics of costumes and steps to arrange harmonious formation that meets the emotions the colors reflect.[5]

\section{Innovative Design of Skilled Movements}

Movements for Dancesport should be arranged and designed properly and reasonably in accordance with the dance theme. Additionally, movements by different body parts or those with different skills should be arranged crosswise to avoid excessive repetition of same steps. Movements are divided into head gestures, arm gestures and leg gestures in terms of body parts, and rotary movements, coordinated movements, jumping movements and bouncing movements in terms of step characteristics. As dancesport increasingly develops, choreography tends to be of highly difficulty and beauty, which requires a fine integration between difficulty degree of movements and aesthetic performance to fully express the art of difficulty and beauty. Hence, audience can appreciate more rotary, ingenious jumping and matching movements. Meanwhile, the order between movements is also arranged elaborately by the choreographer, neither too simple nor too stiff. Instead, different 
movements are connected naturally as if a flowing set of artistic pictures are being on show in a dancing way.

\section{Summary}

Dancesport is characterized by choreography trend and epochal character and the popular style varies from one period of time to another. Currently, from the international perspective, the dancesport choreography tends to integrate movement with quietness and pays more attention to the mobility of dance and its focus transfers from the footwork of dance to their connection. As the dancesport increasingly steps from the competition arena to the art stage, more and more attention is paid to its performability and the dancesport choreography seems more important. Different from traditional choreography, the dancesport choreography possesses its particularity. Nevertheless, no matter which kind of performance form, double, single or group dancesport, the creative factor is essential for choreography.

\section{References}

[1] Zhu Ping. Enterprise technology and development course of sports dancein Colleges and universities. 2010.

[2] Li Yongming, Wang Anrong martial arts curriculum resources developmentand utilization of Shaolin and Tai Chi (Zhongzhou sports) 2010.

[3] Jin Li. Study on of university sport dancing course reform of Journal of Shangqiu Normal University. 2009.

[4] Zhang Qiaozhen, Wang pigeon. Sharing status and way of dance sportsresources in Colleges and Universities -- Study on the current situation ofZhejiang province university sports dance resources Zhejiang sports science community. 2009

[5] Zhao Ying. The "school-based sports dance curriculum" the necessity and feasibility of developing the Institute of higher education research. 2008.

[6] Jing Yonggen. Sports dance in the sports curriculum resource development in mass oriented Journal of Shanxi Agricultural University. 2006 